\title{
Violência e inserção social do jovem de periferia urbana
}

\author{
Leila Maria Ferreira Salles' \\ Joyce Mary Adam de Paula e Silva \\ Débora Cristina Fonseca \\ Universidade Estadual Paulista, Rio Claro - SP - Brasil
}

\begin{abstract}
Resumo: Este trabalho tem por objetivo analisar modos de inserção social de jovens pertencentes aos estratos sociais mais desfavorecidos da população na comunidade onde vivem. Para tanto, foram organizados grupos focais com jovens que diferiam entre si quanto ao protagonismo de situações de violência. A análise indica que os jovens considerados protagonistas de violência tendem a se distanciar dos não protagonistas nas atividades que realizam, nos lugares que frequentam, nas formas de lazer que preferem e nas expectativas de vida futura que constroem. As interações de aproximação estão pautadas por estilos de vida semelhantes, e o afastamento se institui pela exacerbação de interesses específicos e pela acentuação da diferença. $\bigcirc$ estudo evidencia uma multiplicidade de modos de inserção social que, ao mesmo tempo que está associada ao pertencimento a um estrato socioeconômico, não é reduzível a ele.
\end{abstract}

Palavras-chave: jovens; violência; inserção social; comunidade; periferia urbana.

\section{VIOLENCE AND SOCIAL INCLUSION OF YOUNG PEOPLE IN URBAN PERIPHERY}

\begin{abstract}
This paper aims to examine methods of social inclusion of young people belonging to disadvantaged social strata of the population in the community where they live. Focused groups were conducted with young people who differed on the role of situations of violence. The analysis indicates that young people considered protagonists of violence tend to distance themselves from not protagonists in the activities that they do, in places they frequent, during leisure activities and also differ about the future life expectations. The study shows that the interactions approach between these youth groups are guided by similar lifestyles and detachment is instituted by the exacerbation of particular interests and the emphasis on the difference.
\end{abstract}

Keywords: youth; violence; social integration; community; urban periphery.

\section{LA VIOLENCIA Y LA INSERCIÓN SOCIAL DE LOS JÓVENES DE PERIFERIA URBANA}

Resumen: Este artículo tiene como objetivo examinar formas de inclusión social de los jóvenes pertenecientes a los estratos sociales menos favorecidos de la población en la comunidad donde viven. Las entrevistas se llevaron a cabo con los jóvenes que diferían en la participación en situaciones de violencia. El análisis indica que los jóvenes protagonistas de la violencia tienden a distanciarse de no protagonistas en las actividades que realizan, en los lugares que frecuentan, en las actividades de ocio y en las expectativas de vida futura. Interacciones de proximidad son guiadas por estilos de vida similares y la

1 Endereço para correspondência: Leila Maria Ferreira Salles, Departamento Educação da Universidade Estadual Paulista, Avenida 24 A, 1.515, Bela Vista - Rio Claro - SP - Brasil. CEP: 13506900. E-mail: leila@rc.unesp.br. 
distancia se establece por la exacerbación de los intereses especiales y el énfasis en la diferencia. El estudio evidencia una pluralidad de formas de integración social que al mismo tiempo que se asocian con la pertenencia a un extracto socioeconómica no son reducibles a ella.

Palabras clave: jóvenes; violencia; inclusión social; comunidad; periferia urbana.

Este trabalho tem por objeto investigar os modos de inserção social de jovens pertencentes aos estratos sociais mais desfavorecidos da população na comunidade onde vivem. No âmbito desta reflexão, procuramos investigar as formas de inserção dos jovens nas ações sociais e nos programas induzidos por políticas públicas direcionadas a essa parcela da juventude. O pressuposto deste estudo é o de que os modos de inserção dos jovens na comunidade diferem conforme eles sejam ou não protagonistas de violência.

Os bairros onde os jovens participantes do estudo residem apresentam grande densidade demográfica e baixos índices socioeconômicos. Na região, há descarte clandestino de resíduos, bolsões de entulhos e lançamento de esgoto in natura nos corpos d'água. Não existem áreas verdes nem áreas destinadas ao lazer da população local. As atividades econômicas estão ligadas ao pequeno comércio e ao setor de serviço informal, representado principalmente por vendedores, cabeleireiras e manicures. Roubos, furtos, brigas, mortes, ações policiais e uso de entorpecentes são fatos cotidianos. É uma região considerada área prioritária pela prefeitura do município para a prevenção da violência de jovens. Em razão das carências socioeconômicas e dos índices de violência urbana e criminalidade que apresenta, é considerado local foco do Programa Nacional de Segurança Pública com Cidadania (Pronasci).

Nessa região da cidade está localizada uma escola pública que atende os jovens da comunidade que frequentam as $5^{\mathrm{a}}$ e $8^{\mathrm{a}}$ séries do ensino fundamental. 0 prédio da escola está bastante depredado, o muro ao redor está quebrado e sua pintura encontra-se suja e pichada. O prédio é escuro e mostra marcas de vandalismo e de invasões que são quase diárias. A ação policial é comum dentro da escola, que denominaremos neste estudo como Escola 1. Ela é apenas uma continuidade de todo o entorno existente.

Como essa escola oferecia, na época em que este estudo foi feito, apenas o ensino fundamental, os jovens, ao término da $8^{a}$ série, eram direcionados para uma escola de ensino médio, localizada em um bairro de classe média, que denominaremos neste estudo de Escola 2. Esta tem uma imagem de ruim e violenta, dados o uso de drogas pelos alunos e o assassinato de um deles, anos atrás, em seu interior. Atualmente, apenas uma pequena parte da construção é utilizada no funcionamento escolar. Diversos pavilhões estão abandonados e desativados. A escola é pouco iluminada, o prédio está mal conservado. A aparência é de abandono, as janelas e os vidros estão quebrados, e as paredes, pichadas.

$\mathrm{O}$ estudo foi realizado com jovens que frequentavam essas duas escolas. O critério para escolha baseou-se no percurso usual dos alunos como descrito, além do fato de que tais escolas, de acordo com a Diretoria de Ensino de Limeira, são as que apresentavam 
maiores problemas relacionados ao protagonismo de violência de alunos no município de Rio Claro. O fato de o estudo ter sido realizado nessas duas escolas se justifica ainda por serem alunos dos ensinos fundamental e médio, e, portanto, com idades diferentes. Supostamente, teriam também interesses e expectativas de vida diferentes, visto que alguns deles já haviam terminado o período de escolarização obrigatória.

\section{Sobre jovens, jovens de periferia e inserção social}

A juventude tem sido considerada como uma categoria social que reúne sujeitos que compartilham a mesma fase da vida. Para as teorias geracionais, estar em uma mesma faixa etária significa partilhar de uma percepção comum que as circunscreve como um grupo com características próprias quando comparado ao de outras gerações. Quando a ênfase recai na juventude como etapa da vida, a distinção entre mundo adulto e mundo jovem é acentuada, sendo a cultura juvenil e os estilos de vida juvenis estudados, analisados e discutidos. No entanto, a socialização do jovem é fruto de um contexto sociocultural específico, em que estão embrenhadas relações de poder e dominação que vão significando a maneira de ser dos jovens. Os processos de escolarização, o uso do tempo livre, a disponibilidade de lazer, entre outros, se inscrevem conforme a condição econômica (Abramovay \& Castro, 2002; Dayrell, 2002).

Pais (1990), sistematizando as concepções mencionadas, afirma que as diferentes reflexões e teorias sobre juventude podem ser agrupadas em duas principais correntes: geracional e classista. A corrente classista questiona a homogeneidade proposta pela corrente geracional na medida em que as diferenças sociais e culturais entre os jovens são interpretadas como produtos das desigualdades estruturais de uma sociedade capitalista. As teorias classistas, ao postularem que o modo de ser jovem tem estrita relação com o estrato socioeconômico ao qual ele pertence, desmascaram a aparente homogeneidade da juventude, que é sublimada nos discursos políticos e nas intervenções administrativas. Para a corrente classista, os estilos musicais, a forma de se vestir, os gostos e as preferências, os estilos de vida e os espaços frequentados pelos jovens são produtos diretos das condições econômicas em que vivem. Nesse sentido, podem ser interpretados como símbolos de pertença a uma determinada classe social e como forma de resistência à ideologia dominante.

Neste texto, consideramos que juventude refere-se a uma etapa de vida, significada pela cultura, que é vivida de forma distinta segundo os estratos sociais aos quais os jovens pertencem. Há uma associação com a faixa etária, mas há, igualmente, uma significação do modo de ser jovem que é dado pelas condições específicas dos estratos sociais aos quais pertencem e que determinam modos específicos de inserção social.

A representação de que os modos de ser dos jovens estão relacionados aos estratos sociais a que pertencem contribui para que a juventude mais empobrecida seja olhada como um segmento ameaçador e perigoso (Sposito, 2001; Silva, Salles, Villanueva, Revilla, \& Bilbao, 2010; Coimbra \& Nascimento, 2003). A referência à periferia neste estudo tem por intenção situar as análises nos modos de inserção dos jovens moradores 
na periferia urbana pobre da cidade. A qualificação ou adjetivação "periferia pobre" se impõe neste estudo tendo em vista que, mesmo que na periferia urbana das cidades hoje seja possível encontrar altos padrões urbanísticos, representados tanto pelos condomínios horizontais como pelos verticais, há ainda, segundo Baltrusis e D'Ottaviano (2009), uma segregação socioespacial nas cidades. Assim, se não podemos entender toda periferia como pobre e o centro como rico, a distribuição socioespacial passa a ser um fator importante nas análises. Desse modo, ser jovem, pobre e morador da periferia implica uma multiplicidade de questões, entre as quais a segregação, a exclusão social e representações de periculosidade.

Em geral, o jovem pobre é associado à periculosidade por habitar locais que são percebidos como degradante em termos sociais e morais. Difunde-se uma percepção que tende a igualar jovens pobres e de periferia como desordeiros perigosos. Isso, segundo Castel (2008), justifica políticas voltadas aos jovens nessas condições sociais que visam normatizá-los. As famílias desses jovens são consideradas degradadas e passíveis de ser submetidas a intervenções de especialistas, que prescrevem procedimentos para a normatização de suas condutas, tendo como objetivo a adequada integração das novas gerações à sociedade. Dificuldades escolares, violência, criminalidade e delinquência juvenil são comumente relacionadas ao desajustamento familiar. Isso contribui para uma identificação de jovens da periferia como perigosos e facilita a imposição de políticas de segregação e confinamento dessa população (Wacquant, 2007; Coimbra \& Nascimento, 2003). Assim, viver em um determinado espaço social tem implicações sociais e pessoais, e a exclusão social aparece como categoria explicativa para refletir sobre os modos de inserção social dessa população. A exclusão social, contudo, não se refere a um fenômeno puramente econômico na medida em que envolve formas de dominação sustentadas por relações de poder e por exclusões simbólicas, como estigmas e estereótipos (Salles, 2010).

A ideia de exclusão social como categoria explicativa estabelece um "fora e um dentro". Quem está "fora" passa então a ser definido como excluído (Maiolino \& Mancebo, 2005; Lopes, 2006; Ribeiro, 2006). De modo geral, exclusão social se refere a um estado de carência, privação material, segregação, discriminação e precariedade (Castel, 2004; Zaluar, 2004). Castel (2004, 2008), ao discutir a questão da exclusão social, aponta que essa análise pode escamotear um processo de "integração perversa" (Zaluar, 2004) dos jovens na sociedade, pois não há um "dentro" e um "fora", mas processos diferenciados de inscrição de determinados segmentos populacionais na ordem vigente. Para o autor, a exclusão remete a um processo de "desfiliação", ou seja, de perda de vínculos.

Os grupos sociais mais empobrecidos da população, em função da degradação das relações de trabalho e das proteções sociais, estão particularmente sujeitos aos processos de exclusão - processos que são acentuados nos jovens e vêm fortalecer, no imaginário social, a representação de jovem pobre, morador da periferia com violência e periculosidade. Mesmo entre os próprios jovens, essa representação parece existir. 
Os jovens constroem estereótipos uns sobre os outros, discriminam-se entre si e se julgam de forma preconceituosa. Um grupo se contrapõe a outro.

Segundo Wacquant (2007), há uma tendência a se "guetificar" essa população. Para ele, gueto consiste em um dispositivo socioespacial que permite a um grupo ostracizar e explorar outro grupo, portador de um capital simbólico negativo que torna todo o contato com ele degradante. O acesso à ajuda pública fica condicionado a normas de conduta que regulam diferentes esferas da vida - como a sexual, a familiar, a educativa - e ao cumprimento de regras, como a assiduidade dos filhos à escola e a inscrição dos filhos adolescentes em programas de treinamento para o emprego. Apropriando-nos das colocações de Wacquant (2007), podemos então considerar que as periferias onde os jovens que participam deste estudo vivem tendem a ser percebidas como um espaço habitado por pessoas degradadas moralmente, que dependem de programas sociais, como o Bolsa Família, como local de desempregados, drogados, traficantes, de jovens potencialmente criminosos, de mães solteiras, de pais considerados irresponsáveis, dos que vivem da prostituição e do roubo.

As propostas, os programas e as intervenções destinados aos jovens que vivem nessas condições, em geral, têm como pilares a preparação para o trabalho, visando à inclusão do jovem no primeiro emprego, à obrigatoriedade da escolarização e à formação para a cidadania (Sposito \& Corrochano, 2005). As políticas sociais contra a exclusão, em geral, se colocam como técnicas, isto é, como se a situação de exclusão fosse passível de ser resolvida pela intervenção de profissionais especializados que tenham por objetivo reparar tal situação, desconsiderando-se a produção social da exclusão.

\section{Método}

\section{Participantes}

Este estudo foi realizado por meio de grupos focais (Gatti, 2005), técnica empregada para a coleta de dados na pesquisa qualitativa que tem por alvo identificar percepções, sentimentos, atitudes e ideias dos participantes a respeito de um determinado assunto, produto ou atividade, dependendo dos objetivos da pesquisa.

Os grupos focais foram realizados com jovens que estavam matriculados nas duas escolas e que diferiam entre si quanto ao protagonismo de violência. Em cada escola foram constituídos dois grupos. Os grupos, denominados aqui de grupo GV, foram formados por jovens indicados pelas equipes gestoras como protagonistas de violência, ou seja, que têm participado de incidentes violentos. Os grupos denominados grupo GNV, também indicados pelas equipes gestoras, foram formados por alunos que não costumam protagonizar situações de violência e/ou participar delas.

\section{Procedimentos}

Na Escola 1, o grupo GV foi constituído por nove alunos: sete meninos e duas meninas. O grupo GNV ficou composto por dez alunos: cinco meninos e cinco meninas. 
Os jovens tinham entre 13 e 15 anos de idade. Na Escola 2, o grupo GV foi formado por oito alunos: seis meninos e duas meninas; e o grupo GNV, por nove alunos, sendo três meninos e seis meninas. Os jovens tinham entre 15 e 17 anos. No grupo GV da Escola 1, dois alunos cumpriram medida socioeducativa de privação de liberdade na Fundação Casa, ambos por porte de arma. Todos eles frequentavam o período diurno, considerado pelos gestores da escola como o de maior ocorrência de situações de violência. Os trabalhos remunerados que exerciam eram esporádicos: guardador de carros em estacionamentos, babá, entregador de panfletos, vendedor de bala, ajudante de pedreiro e ambulante.

Foi solicitado aos participantes que se posicionassem perante temas geradores, como a relação entre os jovens e grupos de jovens, a relação com as instituições sociais e as expectativas de inserção social. Para tanto, solicitou-se que cada aluno descrevesse o que costumava fazer nas horas de lazer, nos horários em que não estava na escola e como se relacionava com seus amigos e outros grupos de jovens, sobre quais espaços sociais, além da escola, frequentava e suas expectativas de futuro.

Foram realizados oito encontros, sendo quatro com cada grupo, com uma duração média de $1 \mathrm{~h} 30$ cada um. Para definir as categorias de análise, as respostas dos jovens foram classificadas e categorizadas em diferentes blocos temáticos, definidos a partir da revisão da bibliografia e dos depoimentos dos participantes. Neste texto, focaremos a análise nos modos de inserção social dos jovens. A técnica empregada foi a análise de conteúdo, que, segundo Bardin (1988), é um instrumental metodológico por meio do qual se busca entender o sentido de uma comunicação.

\section{Resultados}

As categorias de análise dos dados estão relacionadas aos temas geradores dos encontros nos grupos focais: a relação entre os jovens e grupos de jovens, a relação com as instituições sociais e as expectativas de inserção social.

Os jovens participantes do estudo, como apontamos, moram em bairros periféricos da cidade, com alta incidência de violência. A violência nas ruas é relatada pelos alunos das duas escolas. Eles falam de assassinatos, brigas e tráfico de drogas, envolvendo familiares ou pessoas próximas.

Embora haja uma diferenciação nas idades dos participantes da pesquisa conforme frequentem a Escola 1 ou a Escola 2, as questões levantadas por eles foram bastante similares. Porém, quando o parâmetro é o protagonismo de violência, os jovens tendem a se distanciar nas atividades que fazem, nos lugares que frequentam, nas formas de lazer ou nas expectativas de vida futura que constroem e até mesmo nas formas de relacionamento que estabelecem entre si. Nos grupos GV, o diálogo entre eles é marcado pela agressividade. Um jovem constantemente manda o outro calar a boca, dizendo "Você não sabe de nada".

Os integrantes do grupo GV, tanto da Escola 1 como da Escola 2, frequentam lugares que denominam "baladas", danceterias, shows de funk, rodeios, e, ainda, visitam a casa de amigos, jogam bola, videogame e ouvem música. Em sua maioria, não 
frequentam igrejas nem fazem referência a qualquer religião, exceto por algum deboche, com manifestações como risadas dirigidas aos que a frequentam. Em geral, os espaços de convivência são marcados por episódios de violência, muitas vezes protagonizados por eles mesmos:

A maioria dos lugares que a gente ia fechou porque era muitas brigas. Fechou um monte de danceteria.

A violência estava tomando conta, envolve polícia (GV Escola 1).

Em alguns lugares frequentados por eles, a pequena delinquência está presente. Um desses locais, denominado "O Suvaco da Cobra", é descrito como um lugar que é "só trevas", significando que eles próprios o qualificam como um local de baixa reputação:

No Suvaco da Cobra, só vê briga! É briga aqui é briga lá. E, sem calcinha, mulher paga menos. Mas só na noite da minissaia. Se você for com calça cumprida, paga mais (GV Escola 1).

Lá tem um fumando maconha, outro cheirando cocaína (GV Escola 1).

Lembramos que os jovens da Escola 1 que participaram deste estudo têm menos de 16 anos. Percebe-se uma exposição constante desses jovens às drogas, inclusive alguns deles foram apontados pelos demais participantes do grupo como usuários, o que, no entanto, foi negado.

As tentativas de contato desse grupo com os jovens de outras classes sociais, em seus relatos, se pautam por conflitos e agressões. Vão aos shoppings, mas frequentemente brigam e são expulsos pela segurança, o que reforça que os jovens dos estratos mais empobrecidos da população devem ser mantidos a distância. Fatos como esses apontam para o processo de exclusão dos jovens pobres de periferia e reforçam a ideia de periculosidade da juventude pobre e a necessidade de separar esses jovens dos pertencentes aos outros estratos socioeconômicos.

Se eu sou lá do meu bairro e eu for roubar alguma coisa do meu bairro, vou estar sendo errado. Mas se for em outros bairros, aí não. Em bairro rico não (GV Escola 1).

Colocações como essa evidenciam que o processo de segregação social pode vir a ser incorporado na subjetividade dos jovens, reforçando a ideia de periculosidade dos jovens pobres de periferia, e acabam por justificar a segregação desses jovens e por legitimar a exclusão social dessa população (Castel, 2004; Zaluar, 2004).

Mas o grupo de jovens que vive nessa comunidade não é homogêneo entre si: protagonistas de violência se contrapõem a não protagonistas. Um grupo discrimina o outro e tende a se excluir mutuamente, num processo de guetificação (Wacquant, 2007). Os jovens do grupo GV fazem referências a grupos de bandidos que estão presentes na comunidade onde vivem e ao qual dizem pertencer, e falam sobre a possibilidade 
de provocar a morte de alguém como se fosse algo banal, rotineiro. Colocações como essas, mesmo que não sejam verdadeiras, acabam por provocar medo nos demais:

Eles não mexem se a gente não mexer com eles. Se a gente mexer, é perigoso. Então é melhor ficar na nossa (GNV Escola 1).

Eu tinha medo de ir para a escola porque lá eles me ameaçavam. Falavam que iam me bater. As meninas da rua também ficavam falando que ia me bater. Porque elas querem mostrar o poder delas. Mas elas nunca chegaram a me bater (GNV Escola 2).

Eles te massacra na frente de todo mundo, xinga, querem dar uma de bom na saída [da escola]. Vêm empurrando (GNV Escola 2).

Reforçando essas colocações, os alunos dos grupos GNV dizem que andam em grupo como medida de segurança:

Muitas vezes, por segurança, alguém opta por andar com uma pessoa porque, sendo amigo dela, ele não vai deixar ninguém bater (GNV Escola 2).

Tinha uns cara que queria bater no meu amigo, aí eu não deixei. No dia seguinte, cheguei na escola e parecia um formigueiro de tanta gente que veio pra me bater. Daí é perna pra que te quero (GNV Escola 1).

Os jovens pertencentes aos grupos GNV se diferenciam dos integrantes do outro grupo. Em sua maioria, não frequentam "baladas" e poucos frequentam shoppings. As atividades de lazer consistem em ir à casa de amigos, ouvir música, jogar bola, videogame, ir à igreja. Os jovens desse grupo, em geral, parecem ter um lazer mais controlado, frequentando poucos ambientes em que possam ficar mais expostos à violência e à criminalidade:

Eu vou na igreja aos sábados. A gente vai jogar vôlei com a turma da igreja. A gente frequenta grupo de jovens, catequese, encontro (GNV Escola 2).

Ações como frequentar a igreja e não ir ou ir pouco às baladas evidenciam uma diferença entre eles e os jovens integrantes dos grupos GV. Os jovens do grupo GNV participam de cursos e atividades oferecidos pela escola aos finais de semana por meio do Programa Escola da Família, vão ao "centro esportivo do bairro" e frequentam projetos existentes na localidade mantidos pela prefeitura municipal e por organizações não governamentais (ONGs), onde aprendem artesanato. As intervenções sociais no bairro, segundo os alunos do grupo GNV, parecem-nos ensinar ao jovem uma atividade que, no entanto, dificilmente consegue tirá-los de uma situação de subemprego e/ou desemprego. Já os jovens categorizados como protagonistas de violência não participam de atividades dessa natureza. Eles dizem não ter motivos para participar desses projetos, que parecem não ter para eles utilidade prática. 
Os depoimentos a respeito das expectativas pessoais e sobre o futuro profissional em geral são vagas. A maioria diz querer ter um bom emprego, construir uma casa, constituir família, comprar um carro ou ser jogador de futebol. As falas indicam que alguns alunos pretendem continuar estudando, enquanto outros não. Na Escola 1, não foram encontradas muitas diferenças entre os jovens dos dois grupos que falam do desejo de, no futuro, ter um bom emprego, o qual está vinculado ao estudo e à obtenção de um diploma. Na Escola 2, a maioria dos alunos do grupo GV pretende parar de estudar, enquanto a maioria dos integrantes do grupo GNV diz almejar continuar os estudos.

A perda da crença na legitimidade da escola por parte dos jovens dos dois grupos pôde ser verificada. Para os alunos, o diploma que podem vir a obter por meio da escola que frequentam, as quais não oferecem um ensino de qualidade, dificulta a concretização das expectativas de vida futura. A escola é percebida como imprescindível quando se pensa no futuro, mas a relação dos jovens no cotidiano escolar é marcada por conflitos entre seu imaginário sobre a escola e a escola real.

\section{Discussão}

As análises mostram que, em muitos momentos, os modos de inserção dos jovens da comunidade se assemelham e, em outros, se diferenciam. As diferenças se centram nos hábitos de lazer, na participação e na crença nas formas institucionalizadas para o enfrentamento de problemas sociais e para a melhoria da vida pessoal. As interações de aproximação entre esses grupos juvenis, ou seja, aquilo que tende a aproximá-los, estão pautadas por estilos de vida semelhantes, e o afastamento se institui pela exacerbação de interesses específicos e pela acentuação da diferença. Essas diferenças permeiam as relações que os grupos juvenis estabelecem entre si e contribuem para a ocorrência de violência no âmbito escolar.

A questão estrutural da exclusão social, em seus determinantes sociais e econômicos, é praticamente desconsiderada pelos jovens dos dois grupos, embora eles próprios vivam uma vida de pobreza e de exclusão social.

Os jovens considerados não protagonistas de violência parecem acreditar na importância da escola para o seu futuro, frequentam a igreja, cursos e atividades desenvolvidas por ONGs e programas mantidos pelo poder público, mesmo que esses programas sejam intervenções que visam principalmente ocupar o tempo livre do jovem ou ensinar uma atividade que dificilmente consegue tirá-los de uma situação de subemprego e/ou desemprego. Os integrantes dos grupos GNV parecem ser mais otimistas ante o futuro pessoal e da sociedade.

Parece existir, entre esses jovens, uma crença maior nas formas institucionalizadas de resolver problemas sociais. Os jovens considerados violentos parecem agir mais marcadamente dentro daquilo que se configura como protagonismo social negativo: não participam da igreja, não se interessam ou se interessam menos pela escola e por estudar e pelas atividades realizadas por associações de trabalhos voluntários ou pela prefeitura. Há, entre esses jovens, certa identificação com o mundo do crime, o que 
pode estar relacionado à crença de que as instituições educacionais e/ou o trabalho honesto não lhes propiciam condições para acessar bens, poder e prestígio e usufruir disso, caracterizando a perda dos referenciais éticos da vida em sociedade.

A inserção que tais ações promovem é excludente, como diz Kuenzer (2005), voltada ao subemprego, ou é uma forma de inclusão perversa, como diz Sawaia (2011). As políticas públicas indutoras de ações e programas direcionados aos jovens da periferia, a despeito do preconizado em seus objetivos, podem ser compreendidas como uma estratégia de inclusão excludente. Inclusão no sentido de que o objetivo explícito dessas políticas e ações é contribuir para que os jovens tenham acesso à escolarização e ao primeiro emprego, e exclusão por ter seu alcance reduzido, seja quando a referência é o emprego, seja quando a referência é a escolarização.

Lembramos que este estudo se limitou a investigar, por meio de depoimentos, os posicionamentos de quatro grupos de jovens que diferiam entre si quanto ao protagonismo de violência, de modo que as afirmações feitas, embora não sejam passíveis de generalização, levantam a importância de que outros estudos sobre a inserção social de jovens, tanto entre aqueles que participam como entre aqueles que não frequentam esses programas sociais, sejam realizados. Enfim, ao procurarmos nos aprofundar sobre as formas de inserção dos jovens conforme fossem qualificados como protagonistas ou não de violência, evidenciou-se uma multiplicidade de modos de inserção social que, ao mesmo tempo que está associada ao pertencimento a um estrato socioeconômico, não é reduzível a ele. Refletir, então, sobre os modos de inserção social dos jovens é atentar para sua heterogeneidade.

\section{Referências}

Abramovay, M., \& Castro, M. G. (2002). Jovens em situação de pobreza, vulnerabilidades sociais e violências. Cadernos de Pesquisa, 116, 143-176. Recuperado em 8 junho, 2004, de http://www.scielo.br/scielo.

Baltrusis, N., \& D'Ottaviano, M. C. L. (2009). Ricos e pobres, cada qual em seu lugar: desigualdade socioespacial na metrópole paulistana. Caderno $C R H, 22(55)$, 135-149. Recuperado em 4 outubro, 2012, de www.scielo.br/scielo.

Bardin, L. (1988). Análise de conteúdo. Lisboa: Edições 70.

Castel, R. (2004). Las trampas de la exclusión: trabajo y utilidad social. Buenos Aires: Topía.

Castel, R. (2008). A discriminação negativa: cidadãos ou autóctones? Petrópolis: Vozes.

Coimbra, C. M. B., \& Nascimento, M. L. do. (2003). Jovens pobres: o mito da periculosidade. In P. C. P. Fraga \& J. A. S. Iulianelli (Orgs.). Jovens em tempo real (pp. 19-37). Rio de Janeiro: DP\&A.

Dayrell, J. (2002). O rap e o funk na socialização da juventude. Educação e Pesquisa, 28(1), 117-136. Recuperado em 17 maio, 2005, de http://www.scielo.br/scielo. 
Gatti, B. A. (2005). Grupo focal na pesquisa em ciências humanas. Brasília: Liber Livro.

Kuenzer, A. Z. (2005). Exclusão includente e inclusão excludente; a nova forma de dualidade estrutural que objetiva as novas relações entre educação e trabalho. In D. Saviani, J. L. Sanfelice \& J. C. Lombardi (Orgs.). Capitalismo, trabalho e educação (3a ed., pp 77-96). Campinas: Autores Associados.

Lopes, J. R. (2006). "Exclusão social" e controle social: estratégias contemporâneas de redução de sujeiticidade. Psicologia \& Sociedade, 18(2), 13-24. Recuperado em 28 abril, 2008, de http://www.scielo.br/scielo.

Maiolino, A. L. G., \& Mancebo, D. (2005). Análise histórica da desigualdade: marginalidade, segregação e exclusão. Psicologia \& Sociedade, 17(2), 14-20. Recuperado em 24 novembro, 2009, de http://www.scielo.br/scielo.

Pais, J. M. (1990). A construção sociológica da juventude - alguns contributos. Análise Social, XXV(105-106), $\left(1^{\circ}, 2^{\circ}\right), 139-165$.

Ribeiro, M. Exclusão e educação social: conceitos em superfície e fundo. Revista Educação e Sociedade, 27(94), 155-178. Recuperado em 4 maio, 2008, de http:// www.cedes.unicamp.br.

Salles, L. M. F. (2010). Jovens, escola e violência: alguns apontamentos sobre o processo de inclusão e exclusão simbólica. In L. M. F. Salles \& J. M. A. de P. Silva (Orgs.). Jovens, violência e escola: um desafio contemporâneo (pp. 45-70). São Paulo: Unesp, Cultura Acadêmica.

Sawaia, B. (2011). Exclusão ou inclusão perversa? In B. Sawaia (Org.). As artimanhas da exclusão. Análise psicossocial e ética da desigualdade social (11a ed., pp. 7-16). Petrópolis: Vozes.

Silva, J. M. A. de P., Salles, L. M. F., Villanueva, C. F., Revilla, J. C., \& Bilbao, R. D. (2010). A violência no cotidiano juvenil: uma análise a partir da escola. Taubaté: Cabral e Livraria Universitária.

Sposito, M. P. (2001). Um breve balanço da pesquisa sobre violência escolar no Brasil. Educação e Pesquisa, 27(1), 87-103.

Sposito, M. P., \& Corrochano, M. C. (2005). A face oculta da transferência de renda para jovens no Brasil. Tempo Social, 17, 141-172. Recuperado em 15 março, 2009, de http://www.scielo.br/scielo.

Wacquant, L. (2007). Punir os pobres: a nova gestão da miséria nos Estados Unidos (3a ed.). Rio de Janeiro: Revan.

Zaluar, A. (2004). Integração perversa: pobreza e tráfico de drogas. Rio de Janeiro: FGV.

Submissão: 30.7.2014

Aceitação: 2.9.2014 